\title{
A1-A2 Fenestration Tube Technique for Clipping a Ruptured Anterior Communicating Artery Aneurysm
}

\section{A1-A2 Técnica de tubo de fenestração para clipagem de um aneurisma de artéria comunicante anterior roto}

\author{
Nicolás González ${ }^{1}$ John Mosquera ${ }^{1}$ Arturo Ruiz-Aburto ${ }^{1}$ Manuel Morales ${ }^{1}$ Rodrigo Zapata ${ }^{1}$ \\ José Müller ${ }^{1}$ Roberto Díaz ${ }^{1}$ Juan Vásquez ${ }^{1}$ Héctor Zambrano ${ }^{1}$ Franco Ravera ${ }^{1}$ \\ ${ }^{1}$ Department of Neurosurgery, Hospital Regional Rancagua, \\ Rancagua, Chile \\ Arq Bras Neurocir 2019;38:153-156. \\ Address for correspondence Nicolás González, MD, Department of \\ Neurosurgery, Hospital Regional Rancagua, Av Libertador Bernardo \\ O'Higgins 3065, Rancagua, Chile \\ (e-mail: nicolasgonzalez28@gmail.com).
}

\begin{abstract}
Keywords

- intracranial aneurysm

- anterior communicating artery

- microsurgery

Resumo

Palavras-chave

- aneurisma intracraniano

- artéria comunicante anterior

- microcirurgia

A fenestration tube is a clipping reconstruction technique that allows the preservation of critical vessels in aneurysm surgery. A patient with a ruptured anterior communicating artery ( $A C O A)$ aneurysm with a posterior projection was admitted to our neurosurgery unit. $A$ right dominant $A 1$ with rotation of the $A 2$ fork was observed on preoperative computed tomography angiography (CTA). During surgery, we observed that the recurrent artery of Heubner branched off the A2 just distal to the neck of the aneurysm. Successful clipping was achieved by building an "A1-A2 fenestration tube," with preservation of the recurrent artery and of the ACoA perforators. Surgical nuances and the advantages of fenestration tubes are discussed.

O tubo de fenestração é uma técnica de clipagem e reconstrução que permite a preservação de vasos críticos na cirurgia de aneurismas. Um paciente com um aneurisma da artéria comunicante anterior (ACoA) rompido com projeção posterior foi admitido em nosso serviço. A dominante direita $A 1$ com rotação do garfo $A 2$ foi observada na angiografia por tomografia computadorizada (ATC). Durante a cirurgia, a artéria recorrente foi observada ramificando-se a A2 apenas distal ao colo do aneurisma. Uma clipagem bem-sucedida foi alcançada criando um tubo de fenestração "A1-A2," com preservação da artéria recorrente e dos perfurantes da ACoA. Nuances cirúrgicas e as vantagens dos tubos de fenestração são discutidas.
\end{abstract}

\section{Introduction}

Stacking multiple fenestrated clips creates a fenestration tube. ${ }^{1}$ This clipping technique allows reconstruction of complex aneurysms while preserving vascular structures. A critical aspect of anterior communicating artery ( $\mathrm{ACOA}$ ) aneurysm surgery is preservation of the multiple arteries and perforators that are related to the ACoA complex. ${ }^{2}$ The recurrent artery of Heubner arises from the proximal A2 segment in most cases

received

December 15, 2018

accepted

February 27, 2019
DOI https://doi.org/

10.1055/s-0039-1685218. ISSN 0103-5355.
(58\%), and its compromise or occlusion is associated with mediobasal striatum infarction and severe neurological deficits. $^{3}$ The surgeon must consider A1 dominance pattern, ${ }^{4}$ projection of the dome of the aneurysm, ACoA angle, ${ }^{5}$ and rotation of the $\mathrm{A} 2$ fork $^{6}$ when planning treatment strategy. ${ }^{7}$ Aneurysms that project posteriorly with medial rotation of the dome of the aneurysm and of the A2 fork are a challenge because the neck of the aneurysm is hidden and perforators may be in the way of a potential clip.
Copyright $\odot 2019$ by Thieme Revinter Publicações Ltda, Rio de Janeiro, Brazil

\section{License terms}

(c) $(1) \$$ 


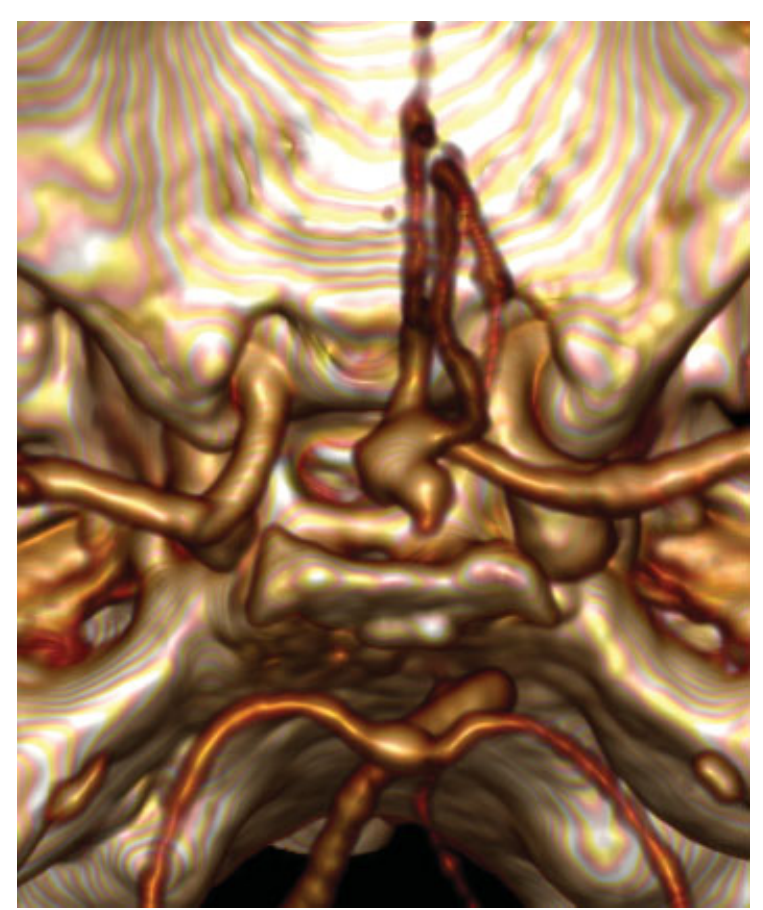

Fig. 1 Preoperative computed tomography angiography.
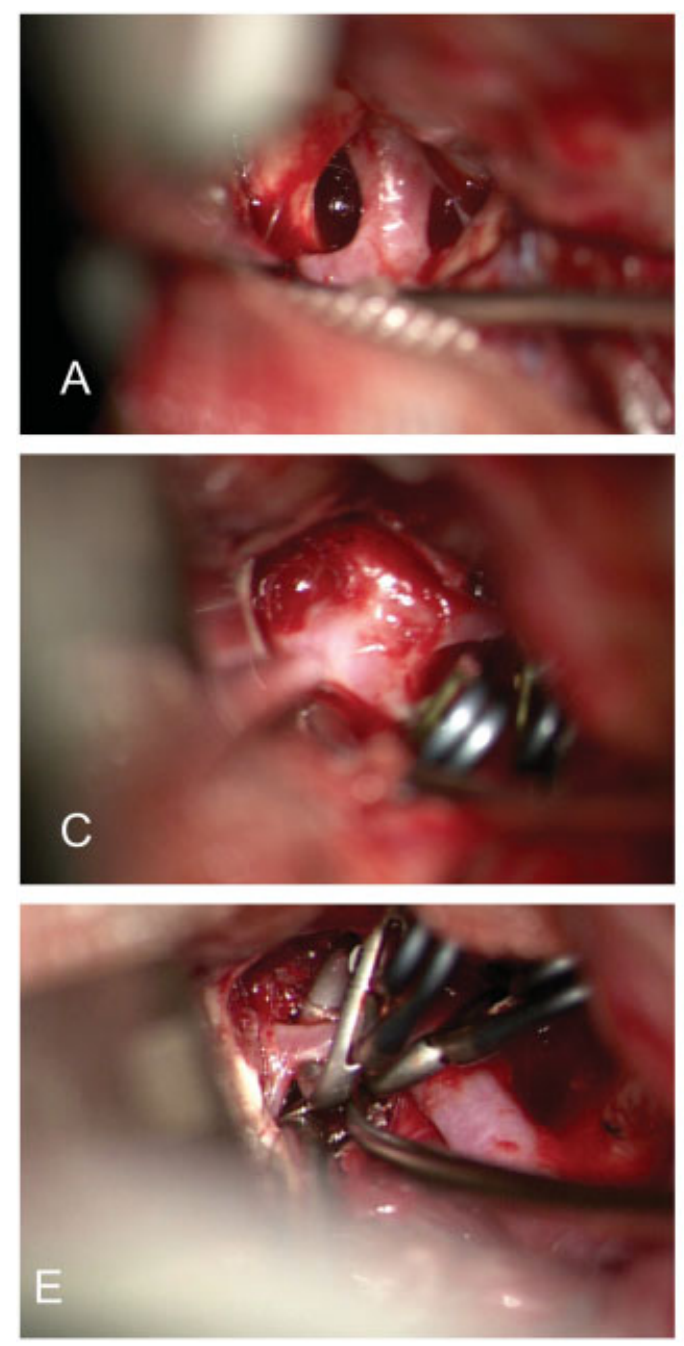

\section{Case}

A 69-year-old patient was admitted to our center with subarachnoid hemorrhage (World Federation of Neurosurgical Societies [WFNS] scale of 1). A computed tomography angiography (CTA) revealed a $4.1 \mathrm{~mm} \times 9.5 \mathrm{~mm}$ ruptured ACoA aneurysm with posterior projection, right A1 dominance and rotation of the ACoA complex, with medial shift of the dome of the aneurysm (-Fig. 1). Surgical treatment was indicated.

\section{Surgical Technique}

Under general anesthesia, the patient was placed on a Mayfield skull clamp, with $20^{\circ}$ of head extension and $30^{\circ}$ of contralateral rotation. A pterional approach was performed from the right side, with interfascial dissection of the temporalis muscle. The orbital roof was flattened with a cutting burr, to increase the angle of view. Under the surgical microscope, initial arachnoidal dissection of the optic and carotid cisterns ( - Fig. 2A) allowed the exposure of the optic nerve and of the internal carotid artery. Blood clot cleansing with saline revealed the carotid bifurcation and ipsilateral
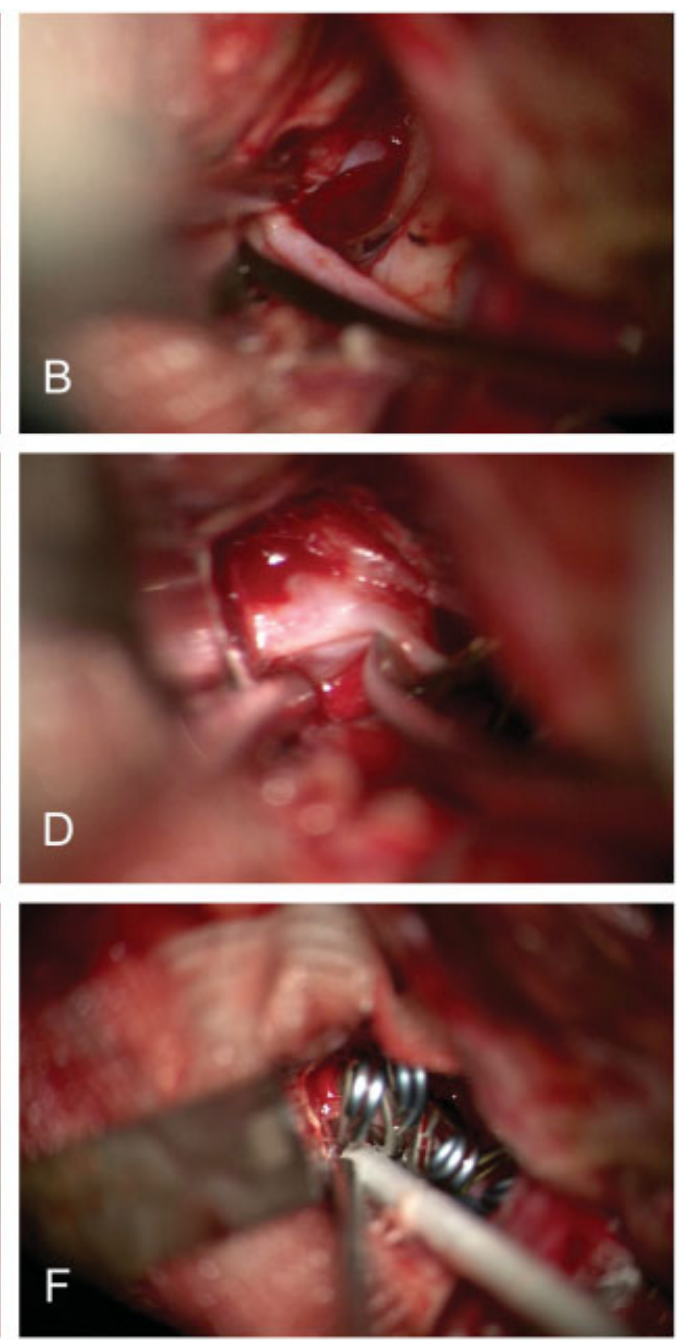

Fig. 2 Surgical technique. 


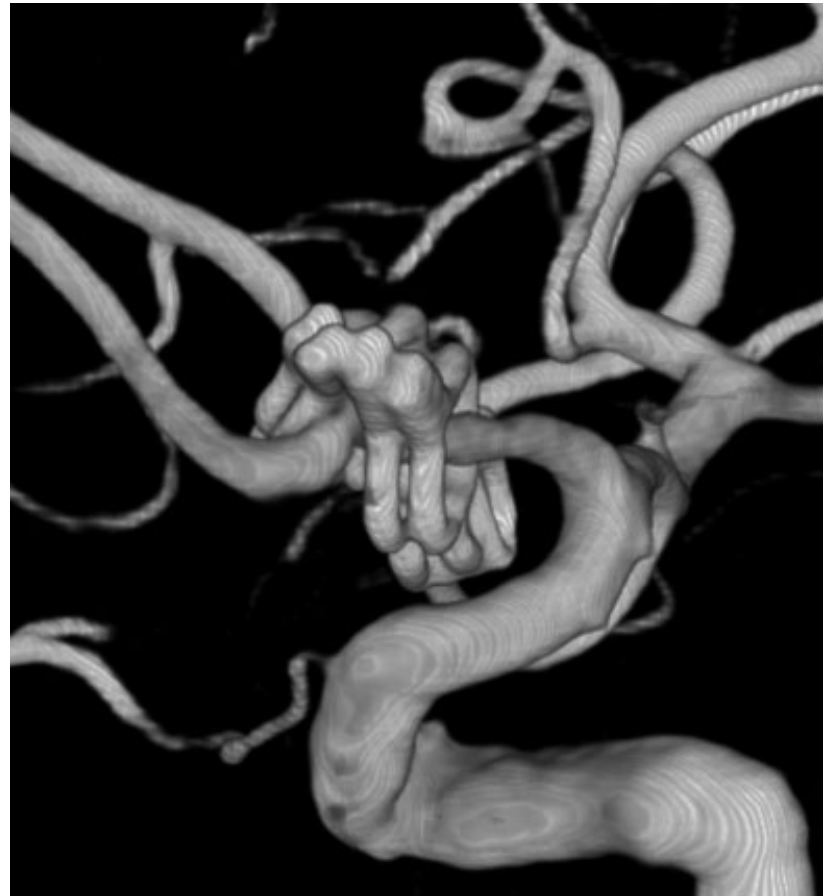

Fig. 3 Postoperative angiography.

A1. Following this artery, we identified the optic chiasm and ACoA complex (-Fig. 2B). Lamina terminalis fenestration ${ }^{8}$ and opening of Liliequist membrane allowed release of cerebrospinal fluid (CSF). Partial gyrus rectus resection ${ }^{9}$ was necessary to expose the bilateral A2. The origin of the recurrent artery of Heubner was localized at the proximal A2. A retractor was placed under the medial frontal lobe with gentle traction. Transitory clipping of both A1 arteries ( $<5$ minutes of total ischemia time) was performed ( - Fig. 2C), and dissection of the aneurysm neck extended medially to the ipsilateral A1-A2 junction (-Fig. 2D). Under direct visualization of the recurrent artery ( - Fig. $2 \mathbf{2 E}$ ), a fenestration tube was completed with two $4 \mathrm{~mm}$ length Yaşargil aneurysm fenestrated clips (Aesculap AG \& Co.,Tuttlingen, Germany) over the A2, and two $6 \mathrm{~mm}$ length fenestrated clips over the A1 (-Fig. 2E). Microdoppler sonography Mizuho Surgical Probe (Mizuho Inc., Tokyo, Japan) confirmed flow on both A2s, and absence of flow in the aneurysm sac.

A postoperative cerebral angiography confirmed the exclusion of the aneurysm from circulation (-Fig. 3), and patency of the arteries of the ACoA complex. The patient had a favorable outcome and was discharged with a Glasgow outcome scale of 5 , three weeks after the surgery.

\section{Discussion}

Drake was the first to introduce the use of fenestrated clips ${ }^{10}$ in aneurysm surgery in 1969. By stacking multiple clips together, the surgeon can create a fenestration tube. This clipping technique allows treatment of complex aneurysms while preserving critical branches and perforators. In ACoA aneurysm surgery, traditional clipping with straight or curved clips may limit surgical exposure because the head of the clip and the artery to be protected are in the way of the line of sight of the surgeon; fenestrated clips are located instead "on top" of the artery, so the exposure is preserved, and less dissection of branches from the aneurysm is needed. ${ }^{11}$ This way, fenestration tubes allow the surgeon the goal of aneurysm exclusion in a more precise and anatomical fashion. Another advantage of fenestration tubes is the increased closing force of multiple clips that allow treatment of giant atherosclerotic or calcified aneurysms, ${ }^{12}$ but great care must be taken to avoid neck tears.

In our case, a right side approach was chosen because the right A1 was dominant. After exposure of the aneurysm, the recurrent artery of Heubner was observed branching just distal to the neck of the aneurysm, at the lateral side of the A2. Fenestrated clips were applied under direct visualization of the recurrent artery, distally from A2 to A1. There were no complications, and exclusion of the aneurysm was possible, maintaining patency in all vessels.

The disadvantages of this technique are the increased number of clips used, and increased clipping time (but less time required to dissect vessels). In cases in which parent artery or branch sacrifice is inevitable, bypass techniques ${ }^{13}$ should be considered.

Overall, we believe that fenestration tube is a valuable technique in the surgeon's armamentarium, and offers advantages over traditional clipping in ACOA aneurysm surgery.

\section{Conclusion}

The A1-A2 fenestration tube is a valuable clipping technique in ACoA aneurysm surgery.

Conflicts of Interests

The authors have no conflicts of interests to declare.

\section{References}

1 Yang I, Lawton MT. Clipping of complex aneurysms with fenestration tubes: application and assessment of three types of clip techniques. Neurosurgery 2008;62(05, Suppl 2): ONS371-ONS378, discussion 378-379

2 Sekhar LN, Natarajan SK, Britz GW, Ghodke B. Microsurgical management of anterior communicating artery aneurysms. Neurosurgery 2007;61(05, Suppl 2):273-290, discussion 290-292

3 Zunon-Kipré Y, Peltier J, Haïdara A, Havet E, Kakou M, Le Gars D. Microsurgical anatomy of distal medial striate artery (recurrent artery of Heubner). Surg Radiol Anat 2012;34(01):15-20

4 Rinaldo L, McCutcheon BA, Murphy ME, Bydon M, Rabinstein AA, Lanzino $G$. Relationship of $A_{1}$ segment hypoplasia to anterior communicating artery aneurysm morphology and risk factors for aneurysm formation. J Neurosurg 2017;127(01):89-95

5 González-Darder JM. ACoA angle measured by computed tomographic angiography and its relevance in the pterional approach for ACoA aneurysms. Neurol Res 2002;24(03):291-295

6 Chen L, Agrawal A, Kato Y, et al. Role of aneurysm projection in "A2" fork orientation for determining the side of surgical approach. Acta Neurochir (Wien) 2009;151(08):925-933, discussion 933

7 Dehdashti AR, Chiluwal AK, Regli L. The Implication of Anterior Communicating Complex Rotation and 3-Dimensional Computerized Tomography Angiography Findings in Surgical Approach 
156 A1 - A2 Fenestration Tube Clipping Technique González et al.

to Anterior Communicating Artery Aneurysms. World Neurosurg 2016;91:34-42

8 Komotar RJ, Olivi A, Rigamonti D, Tamargo RJ. Microsurgical fenestration of the lamina terminalis reduces the incidence of shunt-dependent hydrocephalus after aneurysmal subarachnoid hemorrhage. Neurosurgery 2002;51(06):1403-1412, discussion $1412-1413$

9 Horikoshi T, Nukui H, Mitsuka S, Kaneko M. Partial resection of the gyrus rectus in pterional approach to anterior communicating artery aneurysms. Neurol Med Chir (Tokyo) 1992;32(03):136-139

10 Del Maestro RF. Origin of the Drake fenestrated aneurysm clip. J Neurosurg 2000;92(06):1056-1064
11 Zada G, Christian E, Liu CY, Giannotta SL. Fenestrated aneurysm clips in the surgical management of anterior communicating artery aneurysms: operative techniques and strategy. Clinical article. Neurosurg Focus 2009;26(05):E7

12 Lownie SP, Drake CG, Peerless SJ, Ferguson GG, Pelz DM. Clinical presentation and management of giant anterior communicating artery region aneurysms. J Neurosurg 2000;92 (02):267-277

13 Abla AA, Lawton MT. Anterior cerebral artery bypass for complex aneurysms: an experience with intracranial-intracranial reconstruction and review of bypass options. J Neurosurg 2014;120 (06):1364-1377 